\title{
VIDA E SABERES CULTURAIS COTIDIANOS EM UMA ALDEIA TENTEHAR
}

\author{
$\mathrm{SÁ}^{1}$, Maria José Ribeiro de \\ IFMA/Formadora Núcleo (UFG/UFT/UFMA) \\ SILVA $^{2}$, MARIA DAS GRAÇAS \\ Universidade do Estado do Pará (UFPA)
}

\section{RESUMO}

Este artigo tem por objetivo relatar saberes e fazeres do cotidiano no universo cultural dos Tentehar, descrevendo como vivem e se relacionam no espaço socioambiental em que habitam. O estudo de caso do tipo etnográfico foi realizado na aldeia Juçaral, localizada na porção sudoeste da terra indígena Arariboia, zona rural do município de Amarante do Maranhão. Os registros de campo foram colhidos a partir da técnica de observação participante e entrevistas realizadas com moradores da aldeia. $\mathrm{O}$ estudo mostrou como a vida Tentehar acontece no cotidiano de suas moradias, nas múltiplas atividades cotidianas que desenvolvem no complexo natural roça-mata-rio-igarapé-quintal. Os Tentehar ainda se mantêm sustentavelmente. No entanto, os impactos que hoje castigam a $\mathrm{TI}^{3}$ Arariboia, promovem o desequilíbrio ecológico e por consequência comprometem a sua sobrevivência.

Palavras-chave: Saberes culturais. Cotidiano. Povo Tentehar. Trabalho. Natureza.

\section{ABSTRACT}

1 Pedagoga, mestra em Educação pela Universidade do Estado do Pará - Linha de Pesquisa: Saberes culturais e educação da Amazônia. Atua como Pedagoga do Instituto Federal de Ciência e Tecnologia do Maranhão/Campus Imperatriz.E-mail: maria.sa@ifma.edu.br/mariasa31@hotmail.com.

2 Socióloga, Doutora em Planejamento Urbano e Regional (IPPUR/UFRJ), professora adjunta III da Universidade do Estado do Pará vinculada ao Programa de Pós-Graduação em Educação (PPGED/UEPA), coordena o grupo de Pesquisa Educação e Meio Ambiente (Grupema). E-mail: magrass@, gmail.com.

3 Abreviação de terra indígena. 
The aim of this article is to report on everyday knowledge and practices in the Tentehar cultural universe, describing how they live and relate in the social and environmental space in which they live. The ethnographic case study was carried out in the village of Juçaral, located in the southwest portion of the Arariboia indigenous land, in the rural area of Amarante of Maranhão. Field records were collected from the participant observation technique and interviews with villagers. The study showed how the Tentehar life happens in the daily life of their dwellings, in the multiple daily activities that develop a natural complex of farm-woods-river-small river-backyard that the Tentehar still sustain sustainably. However, the impacts that today punish TI Arariboia promote the ecological imbalance and consequently compromise their survival.

Key words: Cultural knowledge. Daily. Tentehar people. Job. Nature.

\section{INTRODUÇÃO}

O texto relata aspectos da vida em uma aldeia Tentehar, evidenciando saberes e fazeres culturais do cotidiano desse povo. $\mathrm{O}$ estudo de caso foi desenvolvido metodologicamente a partir de pressupostos da pesquisa qualitativa, sustentado em procedimentos da etnografia e cartografia de saberes. O local do estudo foi a aldeia Juçaral, localizada na porção sudoeste da terra indígena Araribóia, situada no município de Amarante do Maranhão. As técnicas para a produção dos dados foram observação participante (ANDRÉ, 2007) e entrevistas (SZYMANSKI, 2011) com moradores da aldeia.

Inicialmente fala-se da organização sociocultural dos Tentehar da aldeia Juçaral descrevendo como a vida acontece no cotidiano de suas moradias, nos diferentes saberes e fazeres que realizam nos seus quintais, deslocamentos diários, valores do cotidiano, funções políticas e públicas, bem como atividades de lazer, enfatizando os processos de resistências e misturas culturais que vêm ocorrendo no âmbito da floresta com o contato cada vez mais frequente com a cultura ocidental.

Na seção subsequente descreve-se o trabalho e os múltiplos saberes que uma família extensa Tentehar realiza para garantir o sustento de todos os membros, a partir dos saberes da agricultura, que envolvem o cultivar e colher alimentos, revelando o compromisso ancestral com a sustentabilidade do espaço em que habitam. Além de 
evidenciar que hoje as famílias Tentehar já sofrem as consequências de impactos ambientais que castigam a TI Araribóia.

\section{O cotidiano da aldeia Juçaral: saberes e fazeres}

A Aldeia Juçaral é uma das 147 aldeias Tentehar que existem atualmente na Terra Indígena Araribóia. Já faz 70 anos que a mãe de Zapuy Guajajara e outros familiares se deslocaram para esse local, nas proximidades do Rio Buriticupu ${ }^{4}$ - zona rural do município de Amarante do Amarante, fizeram uma roça e resolveram ficar morando. Entre idas e vindas, se fixaram no local, pois parece haver certa mobilidade inerente ao jeito de ser dos Tentehar "os índios estão sempre mudando de lugar para outro, de uma aldeia para outra" (ZAPUY GUAJAJARA, 62 anos, março 2014), que talvez esteja relacionada com a dinâmica das famílias extensas Tentehar ${ }^{5}$.

Atualmente, habitam na aldeia Juçaral 80 famílias e há aproximadamente 400 habitantes. Falam preponderantemente a sua língua materna, embora também se comuniquem usando o português. Nesse quesito fazem questão de observar aos pais que falem sempre na língua com seus filhos, essa é uma atribuição dos pais. Quando há reuniões na aldeia, por exemplo, com a presença de karaiw, eles falam as duas línguas, mas há sempre aquele momento em que debatem entre si o assunto na língua mãe, para depois retornar ao português.

Os Tentehar da aldeia Juçaral habitam em moradias construídas de barro em pau a pique, popularmente conhecidas como casa de taipa, com exceção da escola, igreja, posto de saúde e a casa de farinha que foram construídas com tijolos e cobertas com telhas. As casas são cobertas com palhas de babaçu e seus cômodos divididos, geralmente, em sala, quarto e cozinha, com uma área aberta ligada na mesma estrutura aos fundos, onde geralmente tem o fogão de barro $^{6}$, a máquina ou o tanquinho de lavar roupas, o jirau (local onde

$4 \quad$ Mulheres entre 15 e 30 anos.

5 A família extensa é constituída por um número de famílias nucleares, reunidas no espaço da aldeia, sendo geralmente baseada pela liderança de um homem sobre um grupo de mulheres relacionadas por laços de parentesco (WAGLEY; GALVÃO, 1961).

6 Embora boa parte das famílias tenha o fogão a gás, dão preferência para cozinhar os alimentos no fogão de barro. 
lavam os utensílios domésticos), o tear (instrumento de madeira onde as mulheres tecem as redes). Essa área configura-se como um espaço híbrido em que coexistem tradição milenar e tecnologia.

O cacique relembra que esse modelo atual de casa não é a mesma de seus antepassados: "as casas não era assim, era só casa de caibro e palha, não tinha o barro" (ZAPUY GUAJAJARA, 62 anos, 2014). Com apenas um cômodo, eram altas, tinham uma espécie de andar em cima que, ao anoitecer, muitas vezes, usavam como abrigo contra possíveis ataques de animais selvagens, como exemplo, onças.

A chegada da energia elétrica oportunizou que boa parte das famílias, hoje, tenham em suas residências eletrodomésticos, como: aparelho de som, televisão, geladeira e máquina de lavar. Como as casas dispõem de energia elétrica, os moradores entendem ser necessário ter moradias com mais conforto e segurança, e vislumbram a possibilidade de ter casas construídas de telhas e tijolos, em face de incompatibilidade entre energia elétrica e as palhas das coberturas, além do livramento contra animais peçonhentos como cobras e escorpiões. Mas, se por um lado avaliam como benéfica a chegada do mundo tecnológico aos lares da aldeia, por outro, os adultos reconhecem influências negativas, por exemplo, que as mídias sociais provocam no comportamento dos mais jovens.

\begin{abstract}
Através da televisão, muito jovem já participa e vê aquelas coisas, ou novela ou filma né, e trás as coisas ruim, e vai praticando, hoje tem jovem que já usa a droga, que matar, ameaça outro, ele aprende aquilo, pra nós já fez essa mudança de tecnologia. (FRED GUAJAJARA, 33 anos, abril 2014).
\end{abstract}

Nesse sentido, relatou Toinho Guajajara (36 anos) que a influência televisa provoca, inclusive, uma diminuição no interesse dos moradores em participar das suas festas tradicionais. E, embora as festas tradicionais Tentehar sejam o grande acontecimento local, prestigiadas pelos parentes das aldeias Tentehar, ele percebe que, muitas vezes, as pessoas deixam de ir para uma festa tradicional ou para uma cantoria, para ficarem assistindo a uma novela.

Eles não se interessam mais né, eles davam muito valor. De primeiro quando se falava em festa de moqueado, todo mundo falava: é rapaz vai ter festa! 
Hoje não, vai ter uma festa de moqueado em tal lugar, a pessoa nem mais tá nem ligando, não tem mais interesse de ir e participar. (TOINHO GUAJAJARA, 36 anos, abril 2014).

As rodas de conversas noturnas em torno de uma fogueira, hábito cultural em que os velhos transmitem aos mais novos as histórias das caçadas, de caipora, e todas as demais que compõem o imaginário lendário dos Tentehar em suas histórias culturais, também sofreram significativa diminuição com a chegada da energia elétrica, avaliam os moradores. A fogueira simboliza um elo entre os avós e seus filhos, netos; ela proporciona um encontro com o saber da experiência por meio da oralidade, uma cultura de conversa (OLIVEIRA, 2008). Apagar o uso da fogueira pode contribuir para apagar da memória dos mais jovens a rica cultura imaterial dos Tentehar.

Embora, a fogueira não seja acesa com tanta frequência pelos Tentehar da aldeia Juçaral, geralmente acendem-nas nos dias das festas tradicionais para diminuir o frio da madrugada, estes ainda mantêm o hábito de se reunir todos os dias para conversar na frente de suas casas, principalmente no final de tarde e início da noite. $\mathrm{Na}$ frente das suas casas costumam ter geralmente um tronco roliço ou uma tábua de madeira com aproximadamente dois metros que serve como local de acento para conversas com os parentes. Assim como as fogueiras, esses bancos funcionam como um lugar de encontro, um espaço de troca de saberes. Neles, os Tentehar conversam sobre suas vidas e os acontecimentos locais. É através dessa cultura de conversa que, segundo Oliveira (2008), oralmente as comunidades rurais-ribeirinhas transmitem suas vivências, saberes, valores das gerações mais antigas às mais novas.

Enquanto extensão da casa, o quintal serve a múltiplos usos. Os extensos quintais dos Tentehar são um espaço para cultivar a sua vida e cultura. Nele, os Tentehar plantam flores, plantas medicinais, plantas poderosas, fruteiras, muitas das plantas que utilizam para confeccionar seus adornos corporais e criam animais domésticos e silvestres.

O quintal de Imaíra, por exemplo, se destaca pela quantidade de flores que cultiva. Uma amante das flores, ela me contou que esse gosto deve ter vindo de seu parente ancestral Maíra-yr, pois, ainda 
na barriga da mãe, Maira-yr pediu à mãe que colhesse flores para ele cheirar, como registrou Gomes (2002, p. 54): “A mãe acata o pedido do filho, que do seu ventre vai indicando o caminho da morada de Maíra. De tempos em tempos, ele pede para mãe colher flores para ele cheirar".

O quintal de Zapuy Guajajara parece mais uma farmácia natural, porque abriga uma variedade de plantas medicinais, nas diferentes fórmulas que fazem uso cotidianamente. Transmite oralmente os saberes do cuidar-se por meio das plantas que é próprio dos ameríndios. Entre as plantas medicinais, a que mais tem destaque é a maconha, o cumaru, a quina, almesca etc. Além das plantas medicinais, no quintal de Zapuy Guajajara existem algumas plantas mágicas como a pira ka à e a mukamuka, e outras, como: o sabonete, o jenipapeiro na qual se protegem e confeccionam adornos corporais.

Nos quintais é sempre possível encontrar uma sombra debaixo de fruteiras frondosas, como: a mangueira, a jaqueira, a cajazeira, além de pequenas roças onde cultivam milho e mandioca.

$\mathrm{O}$ fundo dos quintais se confunde com floresta nativa. $\mathrm{O}$ rio Buriticupu corre por detrás dos quintais das casas que se situam ao lado esquerdo da comunidade. Nesse terreno alagadiço destacam-se os pés de Juçara e Buriti da qual extraem suco. As talas extraídas das palmeiras buriti e guarumã são usadas para confecção de cestarias.

Entre os animais domésticos criados soltos, existem os cachorros, os gatos e aves, como a galinha caipira e a guiné. É importante ressaltar que se antes os cachorros eram preparados desde cedo para a prática cultural da caça, com a considerável diminuição dessa prática nos últimos anos, os cachorros têm servido apenas para colaborar com a segurança das casas dos seus donos. São vistos em quantidades pelos pátios e quintais, geralmente desnutridos. Entre as suas crenças, acreditam que dá azar matar cachorro, visto que o espírito do cachorro causa perturbação intermitente naquele que lhe tirou vida, que só passa quando o matador ofertar comida em abundância para sete cachorros e comer dessa alimentação. Para os pais que têm filhos pequenos, a matança de um cachorro pode representar ainda a morte do filho que poderá ser levado pelo espírito do cachorro.

É hábito local a domesticação de animais silvestres, como: o macaco guariba ou cuxiú, o periquito e o papagaio, aos quais os Tentehar têm muito apego, são tratados com muito zelo e mimos. 


\subsection{Deslocamentos diários}

Os Tentehar da aldeia se deslocam diariamente para as suas roças, aldeias vizinhas, onde geralmente têm um parente, ou ainda povoado vizinho Campo Formoso, ou para a cidade mais próxima, Amarante do Maranhão. Para realizar seus deslocamentos geralmente usam a moto como principal meio de transporte.

A calmaria do ambiente pacato e tranquilo da aldeia, sem a pressa da cidade, se contrasta com o barulho e a rapidez que a moto proporciona. Também usam a bicicleta e o carro, e é comum ver camionetes da FUNAI e FUNASA a transitar cotidianamente pelo espaço da aldeia, visto que a aldeia Juçaral é uma das portas de entrada para boa parte das aldeias que se situam no lado sudoeste da TI Araribóia. O jumento ou o cavalo é ainda usado para ajudar no transporte do que é produzido na roça. E, se antes, segundo os mais velhos, corriam e se escondiam por trás de uma moita com medo de avião, hoje inclusive já andam de avião.

De primeiro era a pé, tem hora que a gente comprava animais, um burro e munta nele e vai embora a viagem. Hoje tem moto, tem carro, meninada foi jogar pra li, foi de moto. Antigamente não tinha estrada, o acesso era difícil para sair pra cidade, era de pé, a pé mermo. Pessoal tão até deixando a bicicleta. (ZAPUY GUAJAJARA, 62 anos, março 2014).

Recorda Zapuy Guajajara quanto ao hábito de andar descalço, pois quando era criança ia caçar com seu cunhado, andavam pela mata de pés descalços, "e não tinha chinelo não, era de pé de mesmo, mas nem toco quebrava nos meus pés. Corria por cima dos tocos, dos espinhos, não furava nada. Hoje, com o chinelo, o pé ficou fino".

Hoje, os pés e as mãos comandam a moto. A arte de pilotar sobre duas rodas do karaiw foi incorporada pelos Tentehar da aldeia Juçaral com maestria. A rapidez com que conduzem as motos é mais uma diversão, ou o sentir os ares da natureza com mais força sobre seus corpos, do que propriamente preocupação em cumprir horários ou metas. Usam a moto para realizar muitas das suas atividades diárias, como: deixar as crianças na escola, ir à roça, para comprar mantimentos no povoado vizinho, ou seja, fazer quase todos os seus deslocamentos diários. 


\subsection{Os valores do cotidiano}

\section{Imagem 01 - Atividades cotidianas}

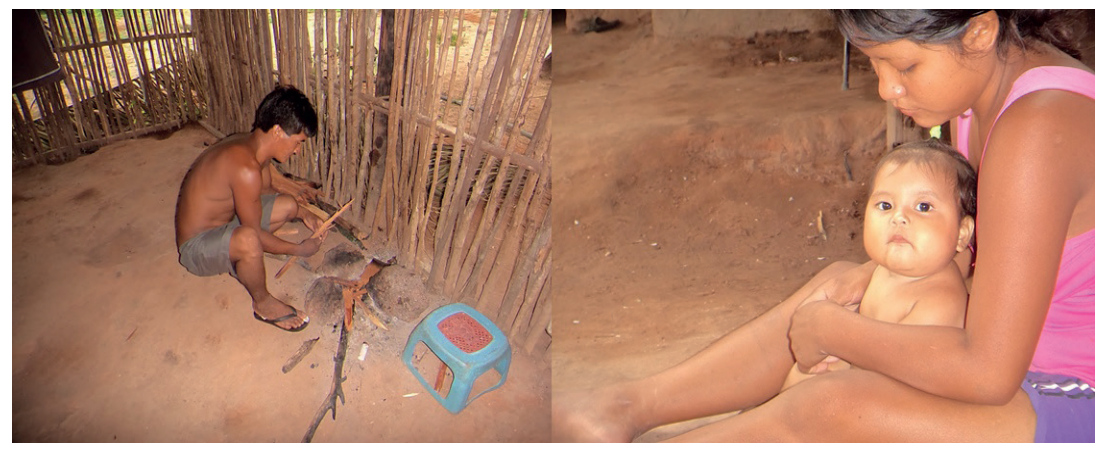

Fonte: acervo fotográfico de Maria José Ribeiro de Sá, 2014.

$\mathrm{O}$ amanhecer e $\mathrm{o}$ anoitecer são marcados pela quietude diária. As famílias costumam deixar as portas das suas casas abertas ao longo do dia, fechando à noite ao dormir, mais pela preocupação de se resguardar da entrada de animais domésticos e peçonhentos, do que pela preocupação com a violência ${ }^{7}$. Geralmente quem visita a aldeia são pessoas conhecidas, ou pessoas autorizadas, visto que por se tratar de um território protegido é proibida a entrada de pessoas estranhas.

O dia passa com a força do presente, sem qualquer preocupação com o futuro, o trabalho na roça ou em casa é calculado na medida de garantir o necessário para viver o presente, talvez por isso não tenham as mesmas preocupações com horários que os ocidentais. Sabem que o que faltar hoje pode ser buscado na casa de um parente. Por isso, Fred Guajajara diz que prefere morar na aldeia, porque, quando não tem em casa, pode contar com ajuda do sogro, do cunhado ou de outro parente. Assim, viver na cidade seria muito mais difícil, pois na aldeia levam a vida se ajudando mutuamente.

7 Para combater a exploração ilegal de madeira dentro da TI Araribóia, os próprios moradores se organizaram por conta própria para prender os caminhões que estejam transportando madeira. Geralmente o que deixa a comunidade em clima de tensão e suspense, é quando chega a notícia de que foi apreendido algum caminhão com madeira pelos "guardiões da floresta" (homens Tentehar que tentam combater a exploração de madeira). 
Esse espírito de solidariedade é visível na forma como os adultos e velhos tratam-se cotidianamente, pois costumam fazer uso da expressão compadre ou comadre. Por ser uma expressão típica dos laços cristãos, Toinho Guajajara lembrou que esse tratamento advém das passagens de fogueiras, prática cultural que costumavam acontecer em épocas juninas à maneira do homem da roça. Assim, a expressão compadre ou comadre reforça os laços de companheirismo para vencer as dificuldades do dia a dia.

Sobre os valores das sociedades ameríndias Munduruku (2012) considera que as epistemologias indígenas diferem da compreensão Ocidental. Para ele, 'grosso modo', é possível afirmar que as sociedades indígenas são sociedades do presente, pois, desde cedo, homens e mulheres são educados para viverem o hoje. Dessa forma, as crianças não são direcionadas para ser alguém no futuro, mas para viverem intensamente o hoje, talvez, por isso, não são ensinadas a poupar ou acumular para o dia seguinte. Assim, seu sistema educativo tem como fundamento a necessidade de viver o hoje.

O valor de levar uma vida tranquila é refletido na liberdade que as crianças Tentehar têm para brincar no espaço dos grandes quintais, na frente das casas, à exceção da hora em que estão na escola, o dia é livre para que possam brincar. Munduruku (2012) descreve sobre os sentidos e significados do viver livre para a criança indígena:

Andar pela mata é mais que um passeio de distração ou diversão; que subir numa árvore é mais que um exercício físico; que nadar no rio é mais que uma brincadeira; que produzir brinquedos é mais que um desejo de satisfação; que ficar horas confeccionando a cultura material de sua gente é mais que uma necessidade. A criança vai entendendo aos poucos que o sentido ganha vida. Suas ações são norteadas pela ausência que mora no seu corpo e que precisam ser completadas por aquilo que dá razão à sua existência. (MUNDURUKU, 2012, p. 69).

Portanto, no decorrer do dia as crianças são apenas colaboradores dos adultos, na maioria das vezes apenas ajudam, buscam ou levam comida para os animais criados em chiqueiros, como os porcos, ou ainda para dar um recado ou trazer algum objeto 
de empréstimo de uma casa para outra. Só deixam de ser criança, após tornarem-se rapazes ou moças, período em que passam a ajudar os pais mais frequentemente.

$\mathrm{O}$ valor de ser uma criança livre para conhecer o mundo talvez seja refletido na forma respeitosa com que as crianças indígenas tratam os pais e os adultos. Os pais não costumam ter muito trabalho quanto ao comportamento dos filhos, a reclamação basta para que a criança/jovem não faça uma coisa que não agrada aos pais. Não vi um filho responder um $\mathrm{pai}^{8}$, ou um pai reclamar a um filho para não ser atendido. Esse fato chamou minha atenção, pois os pais têm o respeito dos seus filhos sem precisar ter que bater nas crianças. Eu não vi qualquer pai ou parente dar uma palmada ou surrar as crianças no período em que estive na aldeia.

$\mathrm{Se}$ as crianças passam a vida preenchendo as lacunas do seu corpo, os velhos "já sentiram a passagem do tempo pelos seus corpos" (MUNDURUKU, 2012, p. 71). Por isso, são considerados sábios e são respeitados por todos. Todo saber sobre a história dos Tentehar tem que passar pela prévia aprovação dos velhos, se eles não o reconhecem como digno de verdade, as pessoas não dão credibilidade ao que está sendo anunciado. Por isso, são geralmente consultados antes que se tome qualquer decisão importante na aldeia Juçaral, explicou Zapuy Guajajara.

\subsection{O lazer do cotidiano}

O futebol é a grande paixão das novas gerações Tentehar. É no campo de futebol que é possível encontrá-los quase sempre a partir da segunda metade da tarde. Homens e mulheres, solteiros e casados jogam futebol na aldeia Juçaral. Os gêneros não se misturam, há o time dos homens e o time das mulheres, geralmente jogam os/ as solteiros/as contra os/as casados/as. Cada time costuma geralmente ter um líder. O jogo de futebol entre os Tentehar se configura não só como um esporte, mas, sobretudo, como um momento de lazer. É uma competição amistosa, embora também participem de campeonatos nas aldeias ou povoados vizinhos.

8 Embora, segundo Toinho Guajajara (36 anos), alguns jovens já não obedeçam e respondam seus pais, fato que ele atribui por conta de serem influenciados por jovens karaiw do povoado Campo Formoso com quem geralmente mantêm contato. 
O campo de futebol é o lugar ideal para se perceber as mudanças culturais que vem ocorrendo nas relações de gêneros entre os Tentehar. Sem perder de vista a identidade da mulher cuidadora do lar, dos filhos e do esposo, a mais nova geração de mulheres casadas $^{9}$ acrescentou entre as suas várias atividades diárias: o futebol. A mulher pacata, que não falava português e vivia confinada ao âmbito do lar, deu lugar à mulher que joga futebol, fala outra língua e estuda. E, mesmo em minoria, já trabalham em funções públicas ocupando, por exemplo, o cargo de professora.

\subsection{Funções políticas e públicas}

O cacique ou chefe da aldeia é o representante político máximo da aldeia, embora, hoje, como explicou Zapuy Guajajara, já tenha outras autoridades públicas, como: o presidente das associações comunitárias e os servidores públicos da área da saúde e educação.

A função de cacique se caracteriza por ser uma atividade voluntária, em que o cacique se compromete em defender os interesses e os direitos da comunidade fora da aldeia como seu representante máximo. Internamente, no âmbito da aldeia, o cacique trabalha mais como um conselheiro, ou um articulador das decisões a serem tomadas para o bem da comunidade. Como é possível perceber a seguir no comentário de Zapuy Guajajara sobre a sua atuação enquanto cacique da aldeia Juçaral:

O trabalho do cacique não é remunerado. A luta do cacique é pra resolver alguma coisa na comunidade, fazer palestra dentro da comunidade, falar sobre a convivência da gente, lutar unido, falar sobre os direitos que a gente tem sobre as terras, não andar comercializando as coisas da terra. A luta do cacique é pra proteger o que nós tem, lutar sobre a terra para outras gerações que não sabe se defender, quem defende somos nós, que reconhece os direitos e da valor os direitos da gente. Falar sobre a educação, sobre a saúde, o melhoramento dentro da comunidade. Falar, exigir, conviver direito, se a gente não lutar quem é que vai lutar por nós? Principalmente os caciques que fica na aldeia, andar respeitando um ao

$9 \quad$ Mulheres entre 15 e 30 anos. 
outro, se a gente não criar o respeito dentro de nós, ninguém vai respeitar. $\mathrm{E}$ a comunidade tem que ver as coisas certas. (ZAPUY GUAJAJARA, 62 anos, março 2014).

Zapuy ocupa a função de cacique da aldeia Juçaral há muitos anos. Como explicou, a escolha da sua pessoa para ser o líder da aldeia foi feita não pelos membros da comunidade, e sim pelos velhos da aldeia. A fala de Zapuy evidencia a importância que a cultura Tentehar atribui aos velhos. Segundo Zannoni (1999), para os Tentehar, a velhice não significa decadência, ao contrário, ela representa a síntese entre experiência e cultura, a plenitude do ser Tentehar, por isso, os velhos são valorizados e ocupam a posição social de conselheiros, os depositários da cultura.

Quando eu era jovem, eu principalmente não respondia o mais velho. Sempre sabia respeitar. Eu aprendi assim com o velho, eu assumi não foi pedindo apoio, foi os mais velhos que depositaram a confiança em mim, mas eu fui andando participando das reuniões do encontro, eu fui vendo, aprendendo, ouvindo os mais velhos. Eu nunca ficou na folia da meninada, sempre andava com os mais velhos. (ZAPUY GUAJAJARA, 62 anos, maio 2014).

Nesse sentido, Zapuy disse que não toma qualquer decisão importante, sem antes conversar com os velhos da aldeia, porque ele reconhece que já lutaram uma vida, por isso, eles sabem o que está certo e errado. Também procura manter a comunidade informada e consulta-a primeiro, antes de tomar qualquer decisão, e só age mediante as decisões que a comunidade deliberar. Segundo Pedro Guajajara, para o cacique ser respeitado pela comunidade tem que respeitar as decisões da comunidade, assim não pode agir a sua maneira. Para ele, o cacique deve ter os seguintes atributos: "pra ser cacique a pessoa tem que ser esperto. É uma pessoa que ajuda muito na comunidade, participativo. É pra resolver as questões na comunidade, brigas internas, participar" (PEDRO GUAJAJARA, 33 anos, maio 2014).

O cacique Tentehar é também um guerreiro. Maíra era um grande guerreiro, o pai de Zapuy Guajajara (62 anos) foi grande guerreiro, e hoje ele assume a função de cacique. Se antes o guerreiro 
lutava com a borduna, o arco e a flecha, hoje, a arma do guerreiro é o conhecimento. Assim, é fundamental que o guerreiro participe das reuniões, dos encontros, esteja por dentro do direito indígena para defender os direitos da comunidade. "A guerra de hoje não se trava, portanto, na floresta, mas na cidade" (ZANNONI, 1999, p. 99). Fred Guajajara compreende o guerreiro Tentehar como:

A pessoa que luta pelos direitos, e não para matar os outros, é aquele que tem coragem, está por dentro das coisas da aldeia, pronto para matar ou pra morrer. O guerreiro verdadeiro, não desiste da luta, não se vende, se a comunidade decide para ele fazer ele tem que fazer o que a comunidade quiser. (FRED GUAJAJARA, 32 anos, maio 2014).

Hoje, além do cacique, os presidentes das associações comunitárias também têm o poder de representatividade local. $\mathrm{Na}$ aldeia Juçaral, há duas associações. Aassociação comunitária Zyhatyw e a associação das mulheres artesãs. Através dessas associações, com a assessoria da FUNAI e ONGs, eles são beneficiados com projetos comunitários.

Como previsto em seus estatutos, essas associações têm presidente, secretário e tesoureiro, funções geralmente ocupadas por lideranças locais. As lideranças locais são pessoas que ocupam funções públicas, que já estudaram e, assim, estão preparados para exercer cargos públicos ou ainda participar das reuniões, encontros do movimento indígena organizado. São, geralmente, professores/ as, agentes de saúde, técnicos em enfermagem. Dessa forma, não só o cacique, mas as lideranças que estão à frente das associações, também defendem os interesses da comunidade no âmbito externo.

Os serviços públicos são remunerados e os cargos são ocupados na escola e no posto de saúde da aldeia. Esses cargos são ocupados conforme a formação específica do morador, e são distribuídos entre os membros das famílias extensas que residem na aldeia. Nos últimos anos, os Tentehar têm estudado para que possam ocupar vagas no serviço público local. Contudo, a subsistência das famílias locais advém do trabalho que realizam a partir dos seus conhecimentos tradicionais. 


\section{O Trabalho no cotidiano Tentehar: múltiplos saberes}

Quando Maíra andava neste mundo, os Tentehar não precisavam ir à roça. $\mathrm{O}$ machado e o facão trabalhavam por si mesmos. Sem que ninguém os levassem. As varas de mandiocas caminhavam para os roçados. Era plantar num dia e colher no outro. Maíra mandava a mulher buscar mandioca plantada na véspera [...] Mas a jovem mulher duvidou de que a mulher estivesse crescida, o que fez Maíra zangar e falar: agora você vai esperar todo inverno (estação chuvosa) até a mandioca, arroz, milho, batata e feijão crescer. (ALMEIDA; PANET, 2010, p. 13).

Desde essa época, os Tentehar viram-se obrigados a trabalhar para garantir a sua sobrevivência. Mas Maíra ensinou os Tentehar a produzir seus alimentos, o que plantar e como plantar, a caçar, a pescar, a colher (ZANNONI, 1999). É importante observar que a mandioca desde a época de Maíra, antes do trabalho já era e continua a ser um dos alimentos fundamentais da cultura Tentehar; e a agricultura, por sua vez, mesmo sem o trabalho humano, já existia. É do cultivo da mandioca que os Tentehar obtêm um dos alimentos que mais lhes fornecem sustância, a farinha azeda. Imersa na água, a farinha azeda se transforma no chibé, um dos principais alimentos tradicionais dos Tentehar.

Imagem 02 - Chibé alimento tradicional dos Tentehar

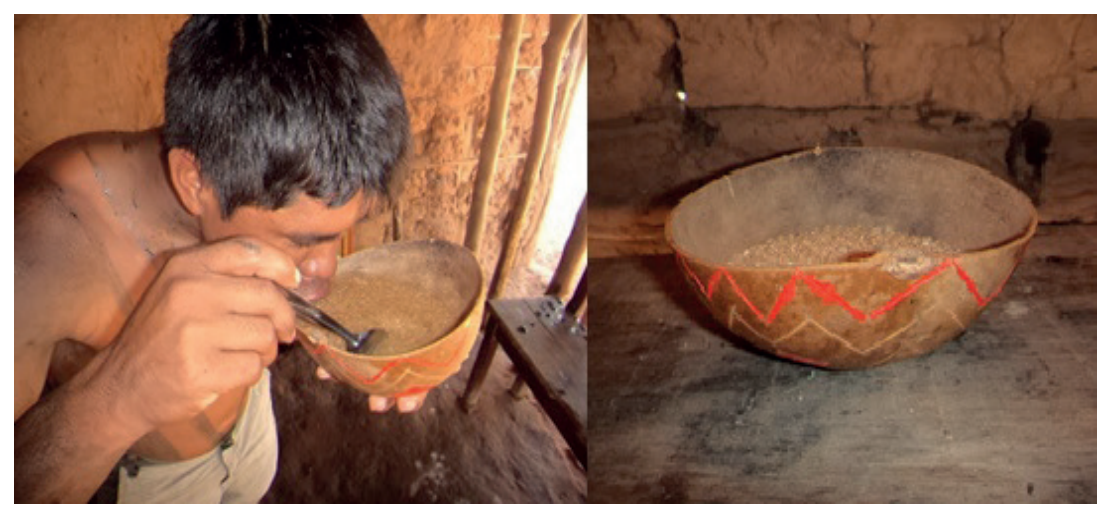

Fonte: acervo fotográfico de Maria José Ribeiro de Sá, 2014. 
O trabalho agrícola através do cultivo de mandioca e produção de farinha dá provas de forte enraizamento e resistência das tradições culturais dos povos ameríndios. Para Oliveira (2008, p. 42), o enraizamento é um "fenômeno fundamental para a condição de sobrevivência das práticas populares". Na cultura Tentehar tanto o cultivo da mandioca quanto a produção de farinha se configuram como um momento de ensinar um saber partilhado com todos os membros da família extensa. "Todo mundo vai pra roça, a gente leva pra plantar também, tem que trabalhar também, porque o pai trabalhando, a gente leva filho, filha pra trabalhar também" (ZAPUY GUAJAJARA, 62 anos, março 2014).

Geralmente, cada família extensa possui um lugar reservado na mata para plantar e caçar, que eles denominam por cento. Cada família possui um cento e, nesse espaço, eles constroem uma pequena casa no entorno da plantação. Na roça, o homem realiza o trabalho pesado, que consiste nas etapas iniciais do roçado como: broque $^{10}$, derrubada, queimada, encoivaramento ${ }^{11}$, aceramento. Já as mulheres ${ }^{12}$ e os filhos dão continuidade ao trabalho com plantio ${ }^{13}$, a retirada dos matos, a colheita e a sua leva.

Enquanto o trabalho da roça é dividido, o trabalho de fazer a farinhada é um momento em que todos os membros da família extensa se juntam. Pais, mães, avós, irmãos, primos, sobrinhos, netos. $\mathrm{Na}$ aldeia Juçaral há uma casa de farinha onde todos os moradores e parentes de outras aldeias, geralmente, com a sua família utilizam para produzir a farinha. A farinhada parece mais um encontro, que propriamente um trabalho. Nesse sentido, explica Oliveira (2008) que as casas de farinha se configuram:

Em autênticos espaços de organização social, política, produtiva e de produção simbólica, aspectos que fazem desses lócus de trabalho genuínos espaços de uma pedagogia do cotidiano, por meio

10 Fase em que agricultor utiliza-se de ferramentas manuais, como facão e foice para desmatar a área de mata a ser plantada.

11 Retirada de galhos finos que não foram eliminados com a queimada.

12 De acordo com Zannoni (1999), o trabalho agrícola pode ser visto como essencialmente feminino, porque são as mulheres que dispensam maior parte do tempo na roça.

13 Embora haja produtos que só os homens plantam. 
da qual, as narrativas orais, a expressão corporal, a celebração das crenças e costumes, a afetividade, a solidariedade, a memória social e as relações com a natureza constituem-se nas raízes e nas águas que ajudam a florescer-e-reflorescer autênticas tradições. (OLIVEIRA, 2008, p. 40).

Os Tentehar da aldeia Juçaral plantam além da mandioca: arroz, feijão, fava, milho, batata, banana, inhame, cará, laranja, amendoim etc. O que produzem é somente para subsistência, portanto, não visam o lucro como produto final. "Porque o índio não, ele bota um alqueire, a quantidade que vê que dá conta, porque não índio, ele já vai pra plantar capim, e outra coisa, já tá com o pensamento de destruir" (FRED GUAJAJARA, 32 anos, maio 2014).

Geralmente podem comercializar o excedente, embora seja difícil fazer isso com a produção porque não há estradas que facilitem a passagem de carros, em vista disso, alguns produtos chegam a se estragar na roça. Sem nenhum maquinário ou produtos químicos, as plantações Tentehar são todas orgânicas.

Dessa forma, os saberes do plantar Tentehar são marcados pela preocupação com a sustentabilidade da terra, pois sabem que a natureza pode puni-los severamente, conforme Zapuy Guajajara, os mais velhos não usavam nada da natureza sem antes pedir permissão para espíritos. Embora essa prática não esteja mais arraigada entre as gerações mais novas, as suas práticas agrícolas carregam a herança do respeito e a preocupação de não abusar do que a natureza lhes oferece, pois, se hoje tem, amanhã pode faltar. Por isso, estão sempre a fazer a rotatividade de suas roças, para preservar a terra, o lugar que foi desmatado para a roça não será mais usado até voltar a sua condição original.

Não tocar fogo assim, não tocar fogo em todo lugar, porque a gente não pode fazer isso, porque se não o fogo vai invadindo a mata ai, acabando tudo, caça, pássaro, e aí lá no existe mais nem nada, caça, nem passarin, nem lambu, nem jabuti, nem preguiça, nem mambira, nem nada. Se a gente toca fogo, a gente faz a barrida primeiro, e quando toca fogo, vai tocando, arrodeando a roça, pra ficar aquele fogo só dentro da roça. (ZAPUY GUAJAJARA, 62 anos, abril 2014). 
O trabalho na roça Tentehar é fincado no respeito frente à natureza, visto que a natureza não é um produto a ser consumido, cada ser que nela habita é portador de vida, por isso, devem cuidar para manter as vidas que nela habitam. Para Oliveira (2008, p. 48), no imaginário e nas práticas sociais das comunidades rurais ribeirinhas, o trabalho é entendido "como o cultivar do ser e da natureza, o que implica o cuidar, preservando e desenvolvendo a sócio e biodiversidades". Nesse sentido, Leff (2010), ao falar de uma economia rumo a um futuro sustentável como critério para uma nova racionalidade ambiental frente à crise ambiental que se vive, propõe:

Desmontar a racionalidade econômica instrumental orientada para gestão dos serviços ambientais e o risco ecológico, para construir uma racionalidade ambiental fundada nos potenciais ecológicos; nas identidades, nos saberes e nas racionalidades culturais que dão lugar à criação do outro. (LEFF, 2010, p. 76).

É importante reconhecer que os saberes ambientais dos povos indígenas são fundados em potencialidades ecológicas que dão lugar à criação do outro, por isso, Leff (2010, p. 94) diz que devemos voltar aos conceitos fundadores das culturas indígenas na América Latina e iniciar uma hermenêutica cultural a partir de seu lugar, devolvendo a economia seu conceito de oikos, como a casa da "Mãe Terra".

Imagem 03 - Limpeza da roça Tentehar

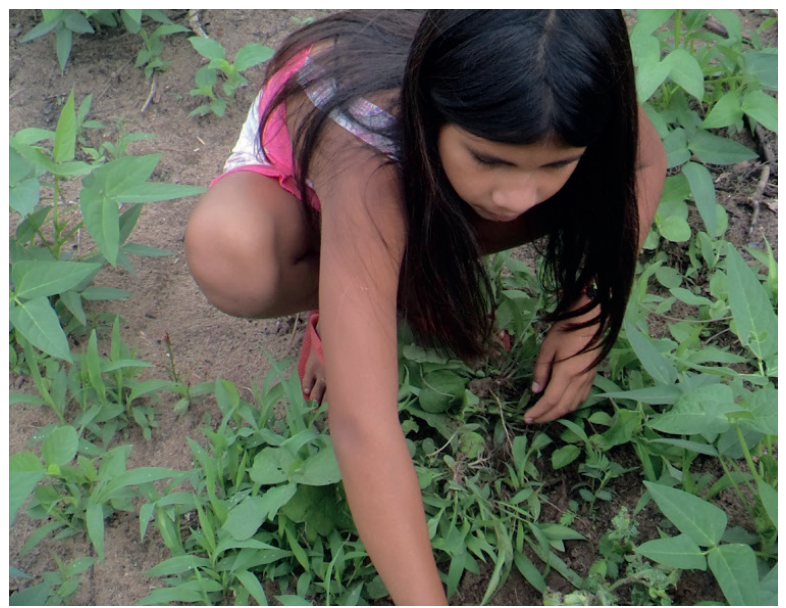

Fonte: acervo fotográfico de Maria José Ribeiro de Sá, 2014. 
A agricultura é apenas uma das práticas sociais produtivas dos Tentehar que, de forma articulada, combinam a prática da caça, da pesca, coleta, ciclicamente, e, dessa forma, ecologicamente potencializam a sua subsistência. É na combinação ecológica dessas diferentes atividades produtivas: plantar, caçar, pescar, coletar que se inscrevem os saberes culturais Tentehar.

O povo Guajajara vive na aldeia com os costumes dos antepassados, vive de caça, pesca e de roça, planta mandioca, arroz, feijão, fava, milho, batata etc. Coleta o mel e frutos como a bacaba, juçara, buriti, bacuri, cajá, naja, tucum, pequi. Caça anta, veado, queixada, caititu, cutia, jabuti, paca. (TOINHO GUAJAJARA, 38 anos, Maio, 2014).

É, portanto no complexo roça-mata-rio-igarapé-quintal (LOUREIRO, 1992), que os Tentehar, da aldeia Juçaral, desenvolvem os saberes e práticas culturais locais. Nos saberes culturais locais se inscreve toda a dimensão material e simbólica da cultura Tentehar, em que o natural e o sobrenatural dialogam constantemente, assim, dão sentido ao seu existir, ao celebrar a vida.

Mas os Tentehar da aldeia Juçaral, hoje, vivem com crescente diminuição das práticas da agricultura, da caça e da pesca. Os impactos ambientais, provocados pela extração de madeira ilegal e das recorrentes queimadas em época de estiagem e a morte de duas das três nascentes do Rio Buriticupu, anunciam tempos difíceis para as futuras gerações.

Sem a mata virgem ficou mais difícil plantar e colher, pois segundo Fred Guajajara "na mata virgem não, só broca, derruba, depois queima e nasce aqueles matos, mais é tudo faiado. Ai só faz a primeira atividade".

Botar roça num baixão que tem na mata, que dar ligume mais sadio. Agora por aqui não, a gente planta e não rende, dá só cinco volume. Agora na mata, num baixão, assim é que produz mais, só de uma linha agente tira quinze volume, e, às vezes, a gente nem dar conta porque nasce muito mato (TOINHO GUAJAJARA, 38 anos, Maio 2014).

Se a mata virgem já vinha sendo diminuída com a venda ilegal de madeira, no ano de 2012 numa grande queimada que se 
deu na TI Araribóia, muitas caças que já vinham sendo diminuídas praticamente foram extintas. E aquelas que ainda restaram sofreram uma drástica diminuição. Esta queimada está gravada na memória de todos, porque com suas roças e as caças destruídas pelo fogo. Nesta época restou-lhes como última opção comprar todos seus alimentos na cidade.

A gente desistiu um pouco de trabaiar. Tem muito novo aqui, que trabaia, mas não do jeito que a gente trabaiava. Botavam roça juntos, botavam num cofo só, a gente caçava, pescava. Se tinha quinze pessoa, vinte pessoa na mata, cada qual trazia carne de porco moqueado, carne assada, faz um girau, toca fogo debaixo e quando fica só aquele fogo, depois pega a carne e deixa carne assar sem sal, de guariba, veado, tatu, paca. Agora hoje eu vejo os jovens criando os filhos mais é na carne de gado, carne de frango, carne que não tem vitamina (ZAPUY GUAJAJARA, 62 anos, maio 2014).

A fala de Zapuy demonstra uma realidade passada, marcada pela fartura e abundância da caça na TI Araribóia, onde os membros das famílias extensas, confinados nas suas tocaias na mata, voltavam para suas aldeias com um dos seus principais alimentos tradicionais, a carne de caça moqueada. Era uma época de trabalho solidário na roça, na caçada e/ou na pescaria. O peixe, por sua vez, com o estreitamento e a diminuição da profundidade do rio Buriticupu, vem se tornando cada vez mais escasso.

A carne de caça moqueada sem sal, ou ainda, a farinha azeda molhada, o beiju com mel, a batata assada, o quibebe de abóbora e inhame, estavam entre os principais alimentos consumidos por Toinho de Guajajara em sua época de criança na casa de seus avós. Ele lembra que "de primeiro, os mais velhos não tomavam café pela manhã, eles fazia beju, e os meninos ficava botando o beju no mel e comendo". Hoje, se alimentam praticamente dos mesmos alimentos que o Karaiw, e temperos, como o sal e o óleo, foram acrescentados ao cardápio Tentehar. "hoje se não tiver tempero dentro da comida, ninguém come" (TOINHO GUAJAJARA, 38 anos, maio 2014).

Embora não tenham deixado de se alimentar com a caça moqueada ou ainda o seu tradicional chibé, a destruição das roças de maniva e a morte de muitas caças quando da grande queimada de 2012, como relatou Zapuy Guajajara, provocaram desalento, 
tristeza e, consequentemente, a doença e o desânimo para trabalhar. Como consequência, passaram a comprar quase todos os alimentos que consomem na mercearia de Campo Formoso ${ }^{14}$. E, se antes a carne de gado e a de frango era uma exceção, passou a ser a regra na alimentação do Tentehar, substituindo a caça moqueada, que passou a ser a exceção.

Hoje, convivem com o problema de segurança alimentar, principalmente aquelas famílias que dependem exclusivamente da alimentação que advém da roça ou da caça. A inserção cada vez crescente da alimentação industrializada talvez esteja colaborando para aumento de problemas de saúde que não faziam parte da realidade do seu povo, como: o diabetes, a pressão alta, a obesidade, reconhecem alguns moradores. Os Tentehar da aldeia Juçaral acreditam que a mudança nos hábitos alimentares vem provocando o envelhecimento ou a morte precoce dos seus parentes, visto que, se não fosse uma fatalidade de 'morte matada', os velhos Tentehar quase sempre chegavam a ser centenários.

\begin{abstract}
Mel, chibé, cozidão só com água e sal, não tem óleo, quando não tinha óleo, eles comiam mais era carne assada. De primeiro, os mais velhos tinha medo de sal. Ai era dificilmente adoecer. Vivia cem 100 anos, não tinha cabelo branco. Minha vó mesmo viveu quase 90 anos. (TOINHO GUAJAJARA, 36 anos, maio 2014).
\end{abstract}

Para Zapuy, a mata queimada não é o único fator para a mudança nos hábitos alimentares dos Tentehar, como relatou, os jovens de hoje não trabalham tanto quanto os de antigamente. Para Zapuy, a diminuição do trabalho entre os jovens Tentehar é decorrente do assistencialismo promovido pelo governo federal, pois "Antes da FUNAI, os índios mesmo produziam. Aí veio a cesta básica, aí os índios pararam. Aí quando chegou a bolsa preguiça (bolsa família), aqui acabou tudo. Tem muito gente que não trabalha, fica só esperando pela bolsa preguiça (ZAPUY GUAJAJARA, 62 anos, maio 2014).

É aparentemente mais cômodo para os jovens Tentehar viverem agora como à época em que Maíra lhes dava tudo, e não precisavam plantar e nem caçar. O governo federal está ocupando o

14 Povoado de não indígenas vizinho à aldeia Juçaral. 
lugar de Maíra, por isso, talvez muitos entendam que não é necessário trabalhar, visto que dispõem do mínimo para viver o presente.

Entretanto, o governo federal não é Maíra, e as suas políticas compensatórias e de rendimento mínimo, como reconhece Zapuy Guajajara, são passageiras. Assim como a FUNAI não mais distribui cestas básicas, a política de rendimento mínimo, que como o próprio nome sugere, lhes dá alimentação mínima, também pode ser que um dia acabe. Para Santos (2010), as políticas compensatórias, como a bolsa escola e o abono família, por exemplo, são os mecanismos modernos para manter a desigualdade em níveis toleráveis.

De acordo com Munduruku (2012), a concepção de tempo para o indígena é diferente da visão de base ocidental. Compreender as diferenças nas percepções do tempo indígena e a de base ocidental é importante para entender porque os Tentehar não estão preocupados em acumular para o dia seguinte. $\mathrm{O}$ que a primeira vista para o ocidental pode parecer "passividade" ou "preguiça", para o indígena é viver com que o presente lhe dá, pois Maíra e outros encantados da floresta lhes ensinaram a tirar da natureza somente o necessário para o sustento diário.

$\mathrm{Na}$ concepção do tempo indígena, o presente é o único tempo real. O passado é memorial e o futuro uma especulação que quase não entra na esfera mental dos povos indígenas. Isso serve para refletir como isso se choca frontalmente com a concepção linear, histórica que o Ocidente desenvolveu. Para o indígena, o tempo é circular, holístico, de modo que vez ou outra os acontecimentos se encontram sem, no entanto, se chocarem. O passado e o presente ganham dimensões semelhantes e se autorreforçam mutuamente. (MUNDURUKU, 2012, p. 70).

A busca por manter as práticas do passado no presente é uma forma de manter viva na memória os saberes culturais que esse povo construiu historicamente por meio das múltiplas atividades cotidianas que os Tentehar desenvolvem no complexo natural roçamata-rio-igarapé-quintal.

\section{CONSIDERAÇÕES FINAIS}

Assim, foi possível perceber que os Tentehar da aldeia Juçaral vivem em espaços híbridos que dão conta do processo de resistência 
de suas tradições milenares, como também da absorção de valores e práticas culturais ocidentais.

Em atividades cotidianas, como o caçar, o plantar e o coletar, por meio da interação ecológica sobrenatureza/natureza se ancoram seus saberes culturais e, por conseguinte a dimensão material e simbólica da cultura desse povo. Assim, se mantêm economicamente por meio dessas atividades, manutenção essa que se vê ameaçada face aos impactos ambientais que castigam a TI Arariboia, já que as queimadas e a extração ilegal de madeira são problemas que vêm provocando o desequilíbrio do complexo roça-mata-igarapé-quintal, e por consequência comprometem seus saberes e práticas culturais tradicionais, sua sobrevivência.

\section{REFERÊNCIAS}

ANDRÉ, Marli Eliza D. Afonso. de. Etnografia da prática escolar. Campinas: Papirus, 2007.

ALMEIDA, Emerson Rubens Mesquita; PANET, Rose-France de Farias. Coleção livros didáticos indígenas e indigenistas. São Luís: SEDUC-MA, 2010.

GOMES, Mércio Pereira. $O$ indio na história: o povo Tenetehara em busca de liberdade. Petrópolis: Vozes, 2002.

LEFF, Enrique. Discursos sustentáveis. São Paulo: Cortez, 2010.

LOUREIRO, Violeta. Amazônia: estado, homem, natureza. Belém: CEJUP, 1992.

MUNDURUKU, Daniel. O caráter educativo do movimento indígena brasileiro (1970-1990). São Paulo: Paulinas, 2012.

OLIVEIRA, Ivanilde Apoluceno de (Org.) Cartografia de saberes: representações sobre religiosidade em práticas educativas populares. Belém: EDUEPA, 2008.

SANTOS, Boaventura de Sousa. A gramática do tempo: para uma nova cultura política. São Paulo: Cortez, 2010.

SZYMANSKI (Org.). A entrevista na educação: a prática reflexiva. $4^{\mathrm{a}} \mathrm{ed}$. Brasília: Líber Livro Editora, 2004.

WALGLEY, Charles; GALVÃO, Eduardo. Os indios tenetehara (uma cultura em transição). Ministério da Educação e Cultura: Departamento de Imprensa Nacional, 1961.

ZANNONI, Claúdio. Conflito e coesão: o dinamismo tenetehara. Brasília: Conselho Indigenista Missionário, 1999. 